\title{
Violaxanthin conversion by recombinant diatom and plant de-epoxidases, expressed in Escherichia coli - a comparative analysis
}

\author{
Monika Olchawa-Pajor1, Monika Bojko², Wojciech Strzałka3, Kazimierz Strzałka2,4 and Dariusz \\ Latowski2⿴
}

1Department of Environmental Protection, Institute of Mathematical and Natural Sciences, State Higher Vocational School in Tarnow, Poland: 2Department of Plant Physiology and Biochemistry, Faculty of Biochemistry, Biophysics and Biotechnology, Jagiellonian University, Kraków, Poland; '3Department of Plant Biotechnology, Faculty of Biochemistry, Biophysics and Biotechnology, Jagiellonian University, Kraków, Poland; ${ }^{4}$ Malopolska Centre of Biotechnology, Jagiellonian University, Kraków, Poland

The purpose of study presented here was to obtain recombinant violaxanthin de-epoxidases (VDEs) from two species. The first one was VDE of Arabidopsis thaliana (L.) Heynh. (WT Columbia strain) (AtVDE) which catalyzes conversion of violaxanthin $(\mathrm{Vx})$ to zeaxanthin $(\mathrm{Zx})$ via anteraxanthin $(\mathrm{Ax})$ in vivo. The second one was VDE of Phaeodactylum tricornutum Bohlin, 1897 (CCAP 1055/1 strain) (PtVDE) which is responsible for de-epoxidation of diadinoxanthin (Ddx) to diatoxanthin (Dtx). As the first step of our experiments, open reading frames coding for the studied enzymes were amplified and subsequently cloned into the pET-15b plasmid. For recombinant protein production, the Escherichia coli Origami $b$ strain was used. The molecular weight of the produced enzymes was approximately estimated to be $45 \mathrm{kDa}$ and $50 \mathrm{kDa}$ for AtVDE and PtVDE, respectively. Both enzymes, purified under native conditions by immobilized metal affinity chromatography, displayed comparable activity in an assay mixture and converted up to $90 \%$ of $\mathrm{Vx}$ in 10 $\mathrm{min}$ in a two step enzymatic de-epoxidation, irrespective of the enzyme's origin. No statistically significant differences were observed when kinetics of the reactions catalyzed by these enzymes were compared. A putative role of the selected amino-acid residues of AtVDE and PtVDE was also considered. Significance of recombinant PtVDE (purified here for the first time ever) is also indicated as a useful tool in various comparative investigations of deepoxidation reactions in main types of xanthophyll cycles existing in nature.

Key words: diadinoxanthin de-epoxidase, diatoms, light stress, violaxanthin de-epoxidase, xanthophyll cycle

Received: 05 May, 2019; revised: 30 May, 2019; accepted: 30 May, 2019; available on-line: 07 July, 2019

๑e-mail: dariusz.latowski@uj.edu.pl

Abbreviations: Asc, ascorbate; $\mathrm{AscH}$, ascorbic acid; AtVDE, violaxanthin de-epoxidase gene of Arabidopsis thaliana (L.) Heynh.; AtVDE, violaxanthin de-epoxidase of Arabidopsis thaliana (L.) Hey$\mathrm{nh}$.; $\mathrm{Ax}$, antheraxanthin; BamH I, restriction endonuclease isolated from Bacillus amyloli; BCIP, 5-bromo-4-chloro-3-indolyl phosphate; DDE, diadinoxanthin de-epoxidase; Ddx, diadinoxanthin; Dtx, diatoxanthin; HPLC, high-performance liquid chromatography; IMAC, immobilized metal affinity chromatography; IPTG, isopropyl $\beta-D-1$ thiogalactopyranoside; MGDG, monogalactosyldiacylglycerol; NBT, $p$-nitroblue tetrazolium chloride; Nde l, endonuclease isolated from

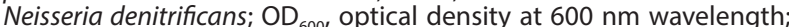
PCR, Polymerase Chain Reaction; PVDF, polyvinylidene difluoride; $P E$, phosphatidylethanolamine; PtVDE, violaxanthin de-epoxidase gene of Phaeodactylum tricornutum Bohlin, 1897; PtVDE, violaxanthin de-epoxidase of Phaeodactylum tricornutum Bohlin, 1897; RCF, relative centrifugal force; RNA, ribonucleic acid; SDS-PAGE, sodium dodecyl sulfate polyacrylamide gel electrophoresis; VDE, violaxanthin de-epoxidase, Vx, violaxanthin; Zx, zeaxanthin

\section{INTRODUCTION}

Under oxygenic conditions, excess of light absorbed by photosynthetic pigments of photoautotrophs can result in photodamage of the photosynthetic machinery. To prevent destructive effect of light and oxygen, all photosynthetic organisms carrying out oxygenic photosynthesis have developed various photo-protective mechanisms. One of them is the xanthophyll cycle which is widespread in nature and displays several types depending on the group of photoautotrophs. All kinds of this cycle involve xanthophyll epoxides de-epoxidation by de-epoxidases under light stress, which results in an increase in the number of conjugated double bonds in these xanthophylls, thus increasing their photo-protective efficiency. The most common types of xanthophyll cycles, i.e. violaxanthin $(\mathrm{Vx})$ and diadinoxanthin (Ddx) cycles, can be distinguished based on the de-epoxidase substrate.

During $\mathrm{Vx}$ cycle under light stress, $\mathrm{Vx}$, with two epoxide groups, is converted into epoxide-free zeaxanthin $(\mathrm{Zx})$ via antheraxanthin $(\mathrm{Ax})$, which is an intermediate with one epoxy group. This reaction is catalyzed by $\mathrm{Vx}$ de-epoxidase (VDE) and occurs in all vascular plants, mosses and some groups of algae, mainly in the green algae (Latowski et al., 2011).

In the Ddx cycle under high light conditions, mono-epoxide - Ddx is transformed into epoxide free diatoxanthin (Dtx). This conversion is catalyzed by an enzyme frequently called Ddx de-epoxidase (DDE). This enzyme has been found in several members of Chromista, first and foremost in brown algae, diatoms and dinoflagellates (Latowski et al., 2011).

Until 2007, it was generally accepted that DDE is the only de-epoxidase in organisms having the Ddx cycle. It was even suggested that in diatoms this de-epoxidase could convert both, Ddx in the Ddx cycle and $\mathrm{Vx}$ in the $\mathrm{Vx}$ cycle, which also exists in diatoms (Jakob et al., 2001). It should be added that all properties of this enzyme have been determined only for a diatom extract but not for a purified enzyme (Jakob et al., 2001; Goss et al., 2005; Latowski et al., 2007).

However, results of these experiments were helpful in comparison of the most important VDEs and DDEs properties: 
1. Both, DDE and VDE are nuclear-encoded and water soluble lumenal proteins that undergo a conformational change when $\mathrm{pH}$ drops due to formation of light-driven proton gradient across the thylakoid membrane; the change in enzyme conformation is accompanied by functional binding of the enzymes to the thylakoid membrane, where the $\mathrm{Vx}$ or Ddx substrates are located;

2. Activity of DDE exhibits a different $\mathrm{pH}$-dependence when compared with VDE:

a) $\mathrm{DDE}$ has $\mathrm{pH}$-optimum at $\mathrm{pH}$ 5.5, whereas VDE around $\mathrm{pH}$ 5.0;

b) DDE is also active at $\mathrm{pH} 7.2$, whereas VDE only at a pH below 6.5 (Jakob et al., 2001);

3. Both, DDE and VDE require non-lamellar lipids such as monogalactosyldiacylglycerol (MGDG) or phosphatidylethanolamine (PE) for their activity, but DDE for optimal de-epoxidation requires a lipid:pigment ratio of around 5, while VDE needs a significantly higher ratio of 30 (Latowski et al., 2004; Goss et al., 2005);

4. In addition to substrate and MGDG, both DDE and VDE need ascorbate (Asc); it was suggested, that not the basic form of Asc, but rather the acid form of ascorbate (ascorbic acid, AscH) is required. DDE has a 3-4 times higher affinity for AscH than VDE; for both enzymes, $K_{\mathrm{m}}$ for AscH was independent of the different $\mathrm{pH}$ values and was found to be $0.075 \mathrm{mM}$ for DDE and $0.290 \mathrm{mM}$ for VDE; in case of Asc, the $K_{\mathrm{m}}$ value for $\mathrm{DDE}$ at $\mathrm{pH} 5$ was determined to be $0.7 \mathrm{mM}$ while for VDE $K_{\mathrm{m}}$ was $2.3 \mathrm{mM}$ at the same $\mathrm{pH}$ (Eskling et al., 1997; Grouneva et al., 2006).

In 2007 the presence of two de-epoxidase-encoding genes in one of diatom species, Thalassiosira pseudonana, was shown (Montsant et al., 2007). One year later it was demonstrated that the genome of another diatom species, Phaeodactylum tricornutum Bohlin, 1897, contains one gene similar to the gene of VDE, labeled as PtVDE, and two VDE-like genes, designated as PtVDL1 and PtVDL2.

All known de-epoxidases belong to the lipocalin family (calycin superfamily) (Bugos et al., 1998; Hieber et al., 2000). A characteristic feature of all known lipocalins is the presence of six or eight antiparallel B-sheets with one, two or three structurally conserved regions (SCRs) (Grzyb et al., 2006). In VDE only two of them (SCR1 and SCR3) were identified (Charron et al., 2005). It is postulated that the characteristic structure of $\beta$-sheets of all lipocalins is responsible for creation of a hydrogenbonded B-barrel sometimes called "calyx" which is nec- essary for substrate or ligand binding. The depth of the hollow in examined proteins is about $40 \AA$ (Holden et al., 1987). The same was postulated for VDE on the basis of substrate specificity analysis.

A comparison between the domain structures of the VDE and diatom DDE proteins shows that both, VDE and all indentified DDEs (TpVDE, TpVDL, PtVDE, PADL1, PADL2), consist of:

1) a cysteine-rich $\mathrm{N}$-terminal domain,

2) a lipocalin domain,

3) a C-terminal glutamic acid-rich domain (Fig. 1).

The cysteine domain, where cysteine residues can form up to six disulfide bridges, is conserved at all cysteine positions in the plant and diatom de-epoxidases and postulated to be essential for activity (Simionato et al., 2015). The distance between SCR1 and SCR3 in the lipocalin domain of diatoms is longer than in known VDEs. The C-terminal Glu-rich domain is less conserved between plants and diatoms than the N-terminal and lipocalin domains. Generally, the C-terminal domains of P. tricornutum DDEs display a lower percentage of charged amino acids, including Glu (Coesel et al., 2008).

Previously, our group had achieved for the first time ever an effective production of two of the three $P$. tricornutum de-epoxidases i.e. PtVDE and PtVDL2 in Escherichia coli. The level of these proteins' production was dependent on the type of E. coli strain. Origami b (DE3) (Novagen) appeared to work better for PtVDE, whereas and BL21 (Novagen) was more proper for PtVDL2 (Bojko et al., 2013b). Crude homogenates of both, PADE and PADL2, had shown an activity in relation to $\mathrm{Vx}$, with dynamic conversion of $\mathrm{Vx}$ into $\mathrm{Ax}$ and $\mathrm{Zx}$, depending on the gene expression level (Bojko et al., 2013b). However, up to now, no comparative analysis of the activity of the purified diatom de-epoxidases and VDE was performed. In this paper, activities of recombinant PADE and Arabidopsis thaliana (L.) Heynh. VDE (AtVDE) are being compared for first time.

\section{MATERIALS AND METHODS}

Construction of plasmids with PtVDE and AtVDE. PtVDE open reading frame was amplified using genomic DNA from 5 day old culture of $P$. tricornutum (CCAP.1055/1 strain), isolated with the help of Genomic Mini AX Plant Gravity kit (A\&A Biotechnology). Diatoms were grown on $\mathrm{f} / 2$ Guilliard medium standard (Guillard \& Ryther 1962) supplemented with $\mathrm{f} / 2$ vitamins and sodium metasilicate (3\%) with artificial 1.6\%

(N) Cys-rich domain

Lipocalin domain

Glu-rich domain (C)

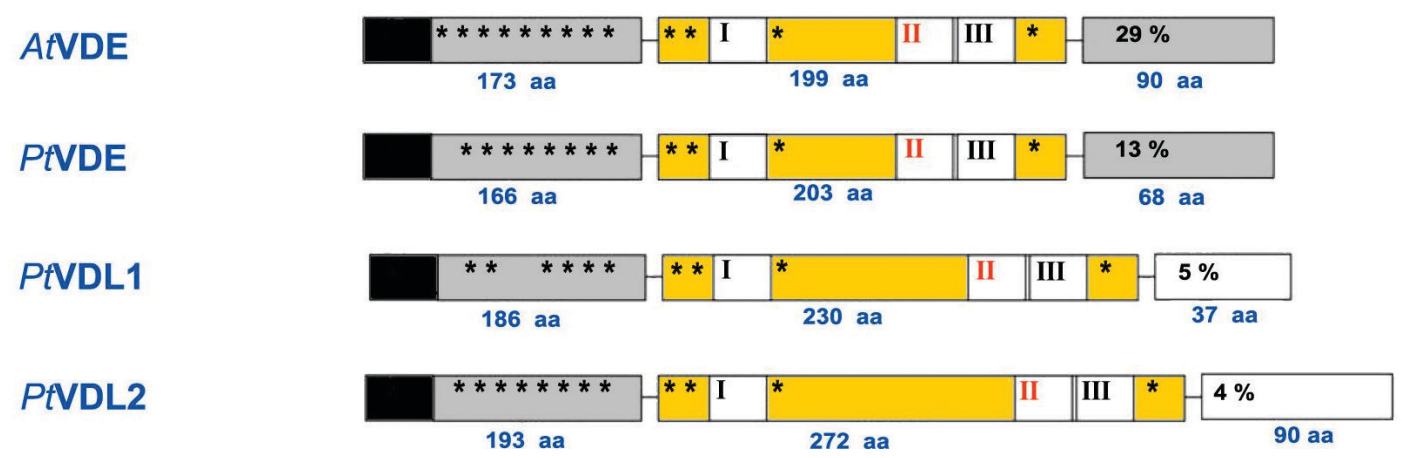

Figure 1. Schematic representation of de-epoxidases.

Black asterisks indicate the positions of conserved Cys residues. The central lipocalin domain contains the lipocalin binding fold. Conserved and divergent lipocalin motifs (roman numbers) are given in black and red, respectively. The C-terminal Glu-rich domain indicates the percentage of Glu residues in this domain (Coesel et al., 2008) 
sea salt (Bio-Active, Tropic Marin) under white light at approximately $40 \mu \mathrm{mol} \mathrm{m} \mathrm{m}^{-2} \mathrm{~s}^{-1}$ with $10 / 14$ photoperiod at $15^{\circ} \mathrm{C}$ (Bojko et al., 2013a). Amplification of PtVDE open reading frame was performed using Pfu DNA polymerase (Fermentas), forward (5'-CCGGATCCTTATTGCTGGGAGGTTTCTC-3) and reverse (5'-GAGCATATGAAGT'T'TCTCGGTGT'TACCAG-3') primers (Genomed), according to Bojko et al. (2013b). PCR was performed using the following thermal condition: initial denaturation (3 $\mathrm{min})$, repeated 35 times cycle of denaturation $95^{\circ} \mathrm{C}(30 \mathrm{~s})$, annealing $56^{\circ} \mathrm{C}(30 \mathrm{~s})$, extension $72^{\circ} \mathrm{C}(2 \mathrm{~min})$ and final extension at $72^{\circ} \mathrm{C}$ for $15 \mathrm{~min}$ (S1000Thermal Cycler, BioRad). The amplified product and $\mathrm{pET}-15 \mathrm{~b}$ vector were digested by NdeI and BamHI restriction enzymes followed by ligation using a ligation kit (Fermentas). The obtained plasmid was named pET-15b/PADE.

The sequence of wild type AtVDE open reading frame uses rare codons with a high frequency and contains several negatively cis-acting motifs which might hamper expression in prokaryotes. Therefore, chemical synthesis of AtVDE open reading frame, optimized for E. coli protein production, was ordered (GENEART). The codons of $A$. thaliana were adapted to the codon bias of E. coli genes. During the optimization process, the following cis-acting sequence motifs were avoided: internal TATA-boxes, chi-sites and ribosomal entry sites; AT-rich or GC-rich sequence stretches; repeat sequences and RNA secondary structures. The optimized open reading frame (length: $1081 \mathrm{bp}$ ) with NdeI site at the 5' terminus and BamHI site at the 3' terminus site was digested and cloned into pET-15b vector as described for PtVDE. The constructed plasmid containing AtVDE was named pET-15b/AtVDE.

$P t V D E$ and $A t V D E$ production and enzyme purification. PET-15b/PAVDE and/or pET-15b/AAVDE were used for transformation of E. coli Origami b (DE3) strain cells (Novagen) (Swords 2003). Bacteria were grown in shaken 1 liter $\mathrm{LB}$ medium at $37^{\circ} \mathrm{C}$. Cultures, at an optical density at $600 \mathrm{~nm}$ wavelength $\left(\mathrm{OD}_{600}\right)$ of approximately 0.6 , were induced with $0.5 \mathrm{mM}$ isopropyl $\beta$-D-1 thiogalactopyranoside (IPTG, Sigma) for 18 hour at $22^{\circ} \mathrm{C}$ (Bojko et al., 2013b). During induction, samples of about $1 \mathrm{ml}$ were collected at $0,3^{\text {td }}, 6^{\text {th }}, 9^{\text {th }}$ and $18^{\text {th }}$ hour, centrifuged and finally kept at $-20^{\circ} \mathrm{C}$ until electrophoresis was performed in order to confirm the enzyme expression. After induction (18h) the cells were harvested by centrifugation $\left(5000 \times \mathrm{g}, 10 \mathrm{~min}, 4^{\circ} \mathrm{C}\right)$. The pellet was suspended in buffer A (50 mM Na $\mathrm{HPO}_{4} /$ $\left.\mathrm{NaH}_{2} \mathrm{PO}_{4}, 300 \mathrm{mM} \mathrm{NaCl}, \mathrm{pH} 7.2\right)$ and sonicated 15 min on ice $(40 \%$ output for $5 \mathrm{sec}$ pulse and $10 \mathrm{sec}$ rest). Subsequently, bacterial lysate was centrifuged $(20000 \times g$, $\left.10 \mathrm{~min}, 4^{\circ} \mathrm{C}\right)$ and incubated on a platform shaker with TALON Metal Affinity Resin (Clontech), equilibrated with buffer A. After incubation the mixture was transferred to a gravity-flow column and the unbound proteins were removed by 5 bed volumes of wash buffer.

Protein bound to the resin was eluted with an elution buffer (150 mM imidazole, $50 \mathrm{mM} \mathrm{Na} \mathrm{HPO}_{4} /$ $\mathrm{NaH}_{2} \mathrm{PO}_{4}, 300 \mathrm{mM} \mathrm{NaCl}, \mathrm{pH}$ 7.2). After purification, eluted fraction, enriched in PADE or AADDE was dialyzed in buffer A. Concentrations of studied VDEs produced in E. coli cells were estimated as follows: (i) total protein concentration in the samples was assayed by the Lowry method (1951); (ii) known amounts of the samples with determined protein concentration were separated by SDS-PAGE (12\% gel) with Coomassie Blue Brilliant staining and next analyzed with a GelAnalyzer software (Laemmli, 1970) to calculate the purity of the isolated enzymes, expressed as percentage of total protein amount; (iii) subsequently, the determined purity of the samples was used to estimate the concentrations of $P A D E$ and $A A \mathrm{VDE}$. Obtained values were used to optimize the enzyme concentration in the assay mixture in the enzyme activity studies (see sub-chapter De-epoxidases activity in this section).

Western-Blot analysis. Proteins separated by SDSPAGE were transferred onto polyvinylidene difluoride (PVDF) membrane with pore size: $0.45 \mu \mathrm{m}$ (ImmobilonP) by the semi dry method. The membrane was blocked by $0.5 \%$ solution of non-fat dry milk with PBS $+0.5 \%$ Tween $20+5 \%$ Blotto for $30 \mathrm{~min}$, and incubated overnight at $4{ }^{\circ} \mathrm{C}$ with monoclonal anti-polyHistidine primary antibody (Sigma), with dilution 1:3000. After washing $(3 \times 5 \mathrm{~min}$, PBS $+0.5 \%$ Tween $20+5 \%$ Blotto) the membrane was incubated with Anti-Mouse IgG-Alkaline Phosphatase antibody produced in goat (Sigma) at a dilution of 1:1000 for $2 \mathrm{~h}$ at room temperature. After washing (PBS $+0.5 \%$ Tween 20) the proteins were detected using p-nitroblue tetrazolium chloride/5-bromo4-chloro-3-indolyl phosphate (NBT/BCIP) (a sensitive substrate for alkaline phosphatase detection reagent, Sigma) (Bojko et al., 2013b).

De-epoxidases activity. Activities of $A \AA \mathrm{VDE}$ and PADE were monitored under darkness, at $20^{\circ} \mathrm{C}$, in a commonly used de-epoxidation assay mixture containing $0.1 \mathrm{M}$ citrate buffer $\mathrm{pH} 5.1,9 \mu \mathrm{M}$ MGDG, $0.33 \mu \mathrm{M} \mathrm{Vx}$ as a substrate and $0.1 \mu \mathrm{M}$ enzyme. The enzyme concentration was selected from five independent tested points ranged between $20 \mathrm{nM}$ and $200 \mathrm{nM}$ of $A \AA \mathrm{VDE}$ or $P A D E$, at which the specific enzyme activity was constant. Reaction was initiated with $\mathrm{AscH}$ which was added to the assay mixture to final concentration of $30 \mathrm{mM}$. Reaction was stopped at the beginning (zero point) and after $1,3,5,10,20$ and $30 \mathrm{~min}$ by mixing $750 \mu \mathrm{l}$ of the assay mixture with $750 \mu \mathrm{l}$ of pigment extraction medium $1\left(\mathrm{CHCl}_{3}: \mathrm{MeOH}: \mathrm{NH}_{3}\right.$; ratio $\left.1: 2: 0,004 \mathrm{v} / \mathrm{v} / \mathrm{v}\right)$ and centrifuged $\left(16000 \times \mathrm{g}, 10 \mathrm{~min}, 4^{\circ} \mathrm{C}\right)$. Bottom, organic phases, with reaction pigments, were collected. After evaporation, samples were solubilized with extraction medium 2 (90\% Methanol-/ammonium acetate (90\% Methanol $/ 10 \% 0.2 \mathrm{M}$ Ammonium acetate): 10\% ethylacetate) and analyzed by high performance liquid chromatography (HPLC) (Yamamoto 1985; Latowski et al., 2002). Volaxanthin was isolated from daffodils Narcissus jonquilla L. petals as described by Havir and coworkers (Havir et al., 1997).

Statistical analysis. The enzyme activity for each tested concentration of the enzyme, as well as purity of the enzymes, were calculated for five independent analyses and mean values are given with standard deviation (S.D.). The average values and standard deviations of results were compared using Student's $t$-test.

\section{RESULTS AND DISCUSSION}

The studied de-epoxidase proteins, PADE and AtVDE, came from two species, $P$. tricornutum and $A$. thaliana, being the model organisms commonly used in the diatom and plant research, respectively. DNA electrophoresis confirmed successful incorporation of both cloned VDE open reading frames into pET15b plasmid (Fig. 2A, B). In turn, successful production of both analyzed enzymes in E. coli, Origami b (DE3) strain cells was confirmed (Fig. 2C, D). Protein production level was examined at the initial step of experiment, i.e. simultaneously with IPTG addition, and then at 3, 6, 9, and 


\section{P. tricornutum}

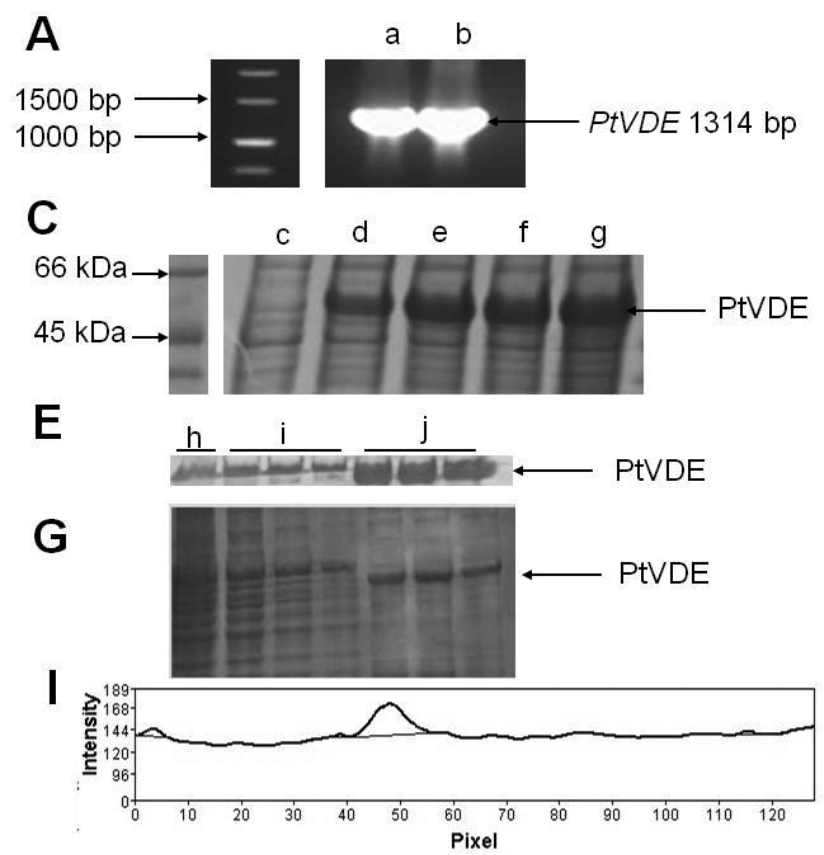

A. thaliana
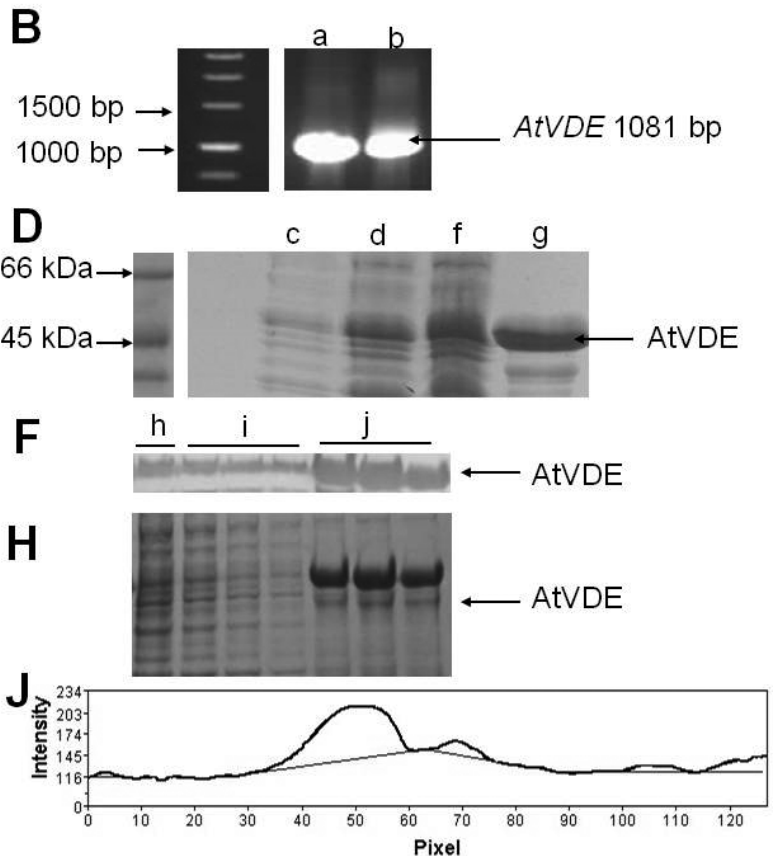

Figure 2. (A, B) Result of a PtVDE and AtVDE open reading frame cloning into pET15b amplified by PCR. Lanes: (a) pET-15b/PtVDE or (b) pET-15b/AtVDE as a DNA template; (C, D) SDS-PAGE analysis of PtVDE and AtVDE production level in E. coli cells. Lanes at: (c) $0 \mathrm{~h}$, (d) $3 \mathrm{~h}$, (e) $6 \mathrm{~h}$, (f) $9 \mathrm{~h}$ and (g) $18 \mathrm{~h}$ after IPTG induction; (E, F) Western-Blot and (G, H) SDS-PAGE analysis of PtVDE and AtVDE samples from different purification steps. Lanes: (h) proteins unbound to resin, (i) proteins weakly bound to resin and (j) imidazole elution fraction with VDEs; $(\mathbf{I}, \mathbf{J})$ Results of densitometry examinations of one of electrophoresis lanes of the " $\mathrm{j}$ " section

$18 \mathrm{~h}$. The level of protein production was the highest, for the both enzymes, at $18 \mathrm{~h}$ after IPTG induction (Fig. 2C, D). The obtained de-epoxidases displayed similar production level and molecular weight of approximately $50 \mathrm{kDa}$ and $45 \mathrm{kDa}$ for PADE and $A A \mathrm{VDE}$, respectively (Fig. 2C, D), which is in accordance with the literature data, where mass of $P t V D E$ is postulated at $49.220 \mathrm{kDa}$ (Bowler et al., 2008) and plant VDE at $43 \mathrm{kDa}$ (Rocholm et al., 1996). Comparable level of PADE and AAVDE production was additionally confirmed by Western-Blot analysis with anti-polyhistidine-tag antibodies (Fig. 2E, F).

SDS-PAGE was also applied to show the efficiency and degree of protein purification (Fig. 2G, H). As the result of recombinant de-epoxidase purification by the IMAC method, three different fractions were collected. First (Fig. 2h) and second (Fig. 2i) fraction contained unbound or weakly bound proteins to the resin. Elution fraction (j) exhibited proteins with high affinity to the resin, including $P A \mathrm{VDE}$ and/or $A A \mathrm{VDE}$ with the highest concentration and purity level (Fig. 2G, H). The enzymes' purity was estimated to be $91.35 \pm 1.78 \%$ and $93.10 \pm 1.58 \%$ for $P t V D E$ and $A A V D E$, respectively (Fig. 2G-J).

In our previous studies, production of PADE featured the highest level among all of the three tested genes of identified de-epoxidases (Bojko et al., 2013b). Here, it is additionally shown, that PADE was produced in cells of applied $E$. coli strain at a similar level to $A A V D E$. In nature, transcript level of PADE was increasing the fastest, among all identified de-epoxidase genes of 48-hourdark-adapted $P$. tricornutum cells, when they were exposed to $175 \mathrm{mmol} \mathrm{m} \mathrm{m}^{-2} \mathrm{~s}^{-1}$ continuous white light, or $25 \mathrm{mmol}$ $\mathrm{m}^{-2} \mathrm{~s}^{-1}$ continuous blue light (Coesel et al., 2008). It suggests that PtVDE can appear as the first active de-epoxi-

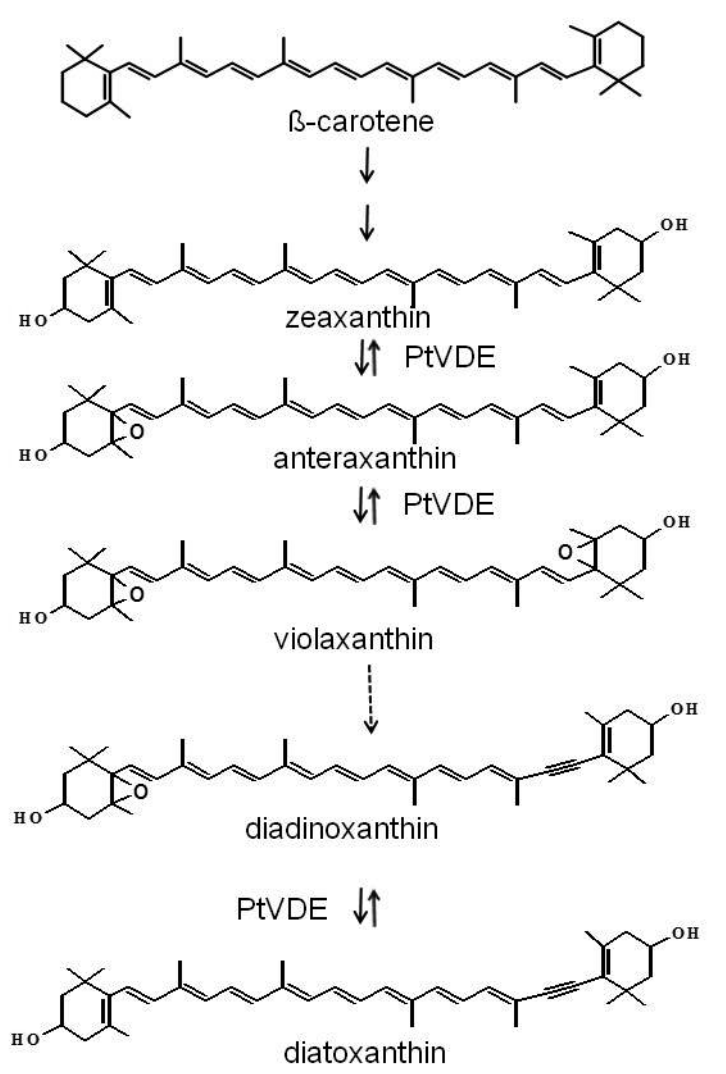

Figure 3. Putative connection of the Vx and Ddx cycles in Phaeodactylum tricornutum; hypothetical conversion step was indicated by a dashed arrow according to Lohr and Wilhelm (Lohr \& Wilhelm, 1999; Lohr \& Wilhelm, 2001) 


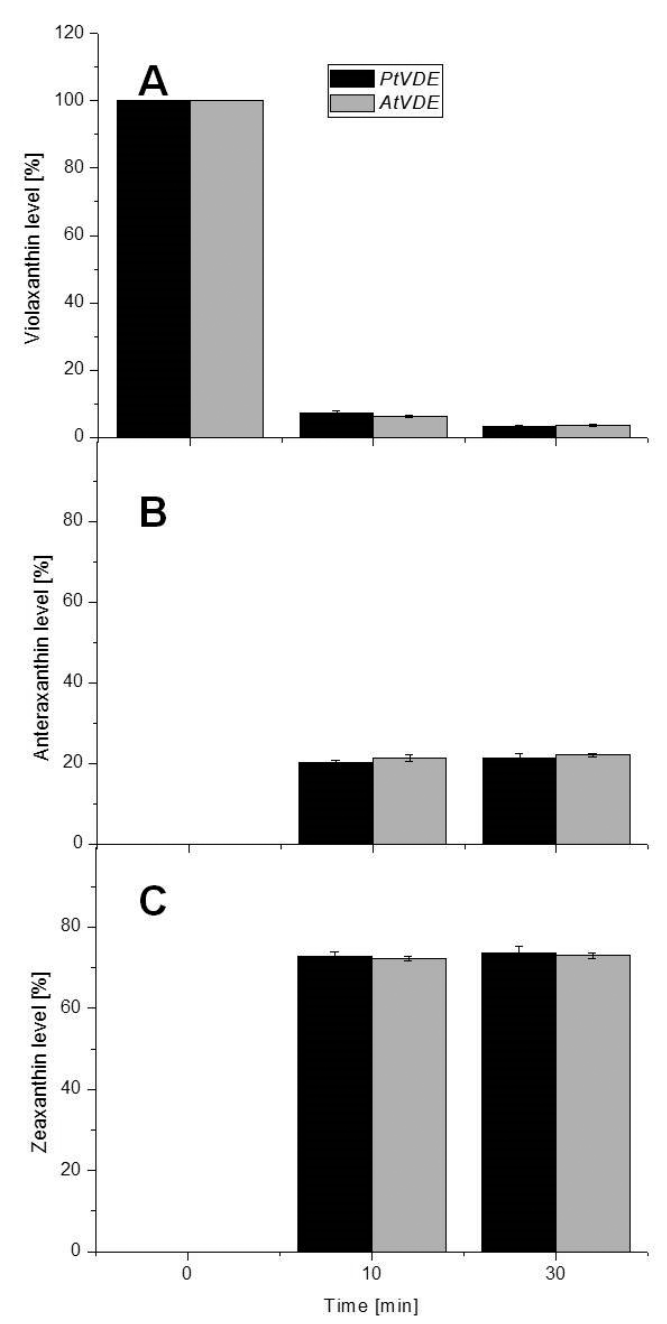

Figure 4. Violaxanthin de-epoxidation (samples collected at 0,10 and $30 \mathrm{~min}$ of reaction) catalyzed by recombinant PtVDE and $A t V D E$, analyzed by level of violaxanthin (A), anteraxantin (B) and zeaxanthin (C) expressed as percent of xanthophyll pigments sum

dase in diatom cells under high light conditions and converts Ddx into Dtx. Perhaps, when light stress extends and Dtx achieves the level which could shift equilibrium of Ddx de-epoxidation in the substrate direction, PADE starts de-epoxidation of $\mathrm{Vx}$, which is synthesized from $\mathrm{Zx}$ and is postulated to be a precursor of Ddx (Fig. 3) (Lohr \& Wilhelm, 1999; Lohr \& Wilhelm, 2001; Coesel, 2008). To verify this possibility, the de-epoxidation of $\mathrm{Vx}$ by recombinant PAVDE and $A \mathcal{N D E}$ was compared in the assay mixture at the same concentration of both enzymes. As Fig. 4 shows, $V_{x}$ is just as good substrate for $A A \mathrm{VDE}$ as it is for PAVDE. Levels of each of three xanthophyll cycle pigments showed no statistically significant differences. Above $90 \%$ of $\mathrm{Vx}$ was de-epoxidized to the comparable levels of $\mathrm{Ax}$ and $\mathrm{Zx}$ at $10 \mathrm{~min}$. since the beginning of the experiment, irrespective of the enzyme type involved (Fig. 4). At $30 \mathrm{~min}$., i.e. at the last detection step, in the presence of both types of enzymes, aproximatelly $3.5 \%$ of $\mathrm{Vx}, 20 \%$ of $\mathrm{Ax}$ and up to $75 \%$ of the final product of the de-epoxidation were detected.

When kinetics of the reactions catalyzed by $A \AA \mathrm{VDE}$ and PAVDE were compared, no statistically significant differences were observed (Fig. 5). The activity appeared

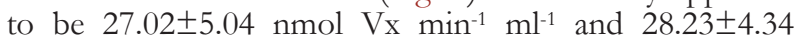

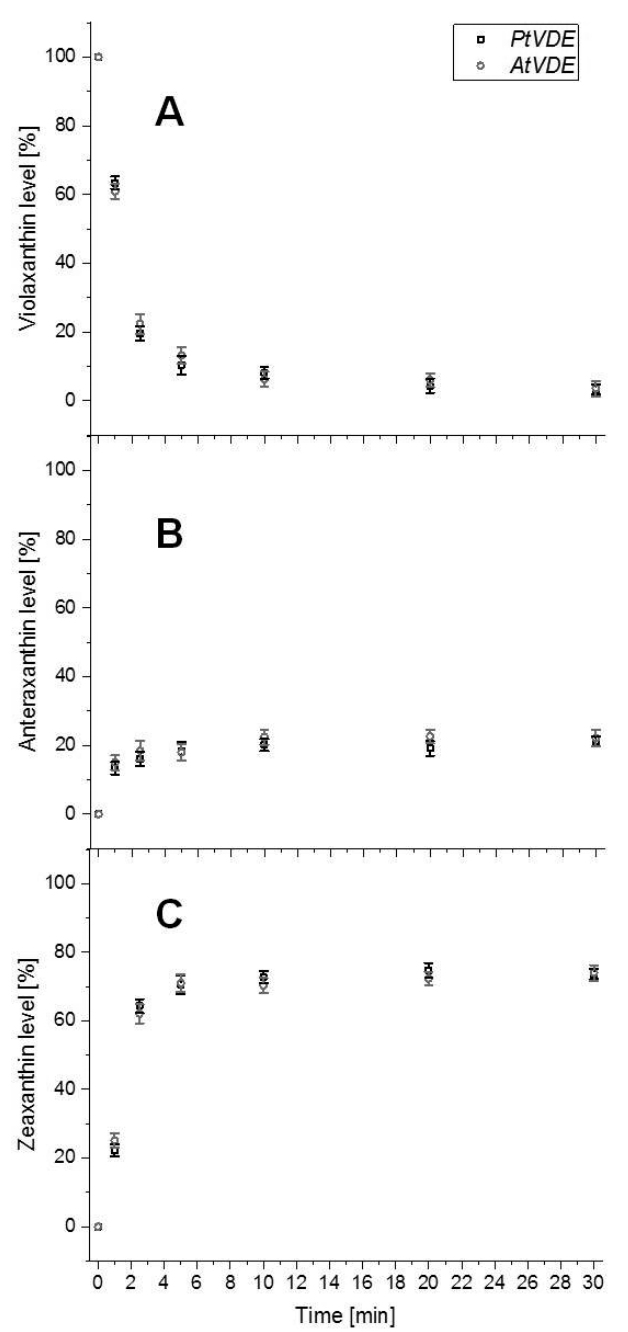

Figure 5. The kinetics of $\mathrm{Vx}$ de-epoxidation (samples collected at $0,1,3,5,10$ and $30 \mathrm{~min}$ ) catalyzed by recombinant AtVDE and PtVDE

nmol Vx $\min ^{-1} \mathrm{ml}^{-1}$ for $A \AA \mathrm{VDE}$ and PADE, respectively.

The obtained results clearly demonstrate existence of substantial similarities in kinetic properties between AtVDE and PADE despite differences in some conserved amino acid residues of these proteins (Table 1). Comparable activity and kinetic properties presented in this paper seem to be supported by the lack of alterations among the six amino acid residues which are suggested to form active site of AAVDE and PADDE (Table 1). These charged or polar, strictly conserved residues, co-localize on one side of the barrel and are indispensable for the enzymatic activity (Arnoux et al., 2009). All of them are also located close to Vx in crystals of the VDE lipocalin domain, and probably they are responsible for substrate binding (Fufezan et al., 2012). However, it is worth to notice that the amino acid composition of PADE2 and PADE1 contains up to 50\% different residues. On the other hand, the most alterations between $A A \mathrm{VDE}$ and PADE are observed among nine amino acids identified as potentially important in the first steps of the enzyme activation caused by a decrease of $\mathrm{pH}$. It is worth to notice that up to 3 of 4 residues suggested to be responsible for $\mathrm{pH}$-dependent conformational changes required for enzymatic activity, such as Asp-98, 
Table 1. Comparative analysis of four groups of amino acid residues of AtVDE and PtVDE important for de-epoxidase activity. Alterations are grey-lighted, *lle-135 in AtVDE is commonly replaced by Leu not only in PtVDE but also in other VDEs working in the Vx cycle

Amino acid residues:

\begin{tabular}{|c|c|c|c|c|c|c|c|}
\hline \multicolumn{2}{|c|}{$\begin{array}{l}\text { Which are suggested to form } \\
\text { active site of de-epoxidases }\end{array}$} & \multicolumn{2}{|c|}{$\begin{array}{l}\text { Potentially important in the en- } \\
\text { zyme activation by a decrease } \\
\text { in } \mathrm{pH}\end{array}$} & \multicolumn{2}{|c|}{ Putatively binding ascorbate } & \multicolumn{2}{|c|}{$\begin{array}{l}\text { Postulated to be located close- } \\
\text { ly to violaxanthin }\end{array}$} \\
\hline AtVDE & PtVDE & AtVDE & PtVDE & AtVDE & PtVDE & AtVDE & PtVDE \\
\hline $\begin{array}{l}\text { Gln }_{153} \\
\text { Tyr }_{175} \\
\text { Asp }_{177} \\
\text { Trp }_{179} \\
\text { Tyr }_{198} \\
\text { Tyr }_{214}\end{array}$ & $\begin{array}{l}\text { Gln } \\
\text { Tyr } \\
\text { Asp } \\
\text { Trp } \\
\text { Tyr } \\
\text { Tyr }\end{array}$ & $\begin{array}{l}\text { Asp }_{98} \\
\text { Asp }_{114} \\
\text { Asp }_{117} \\
\text { His }_{121} \\
\|_{12{ }_{135}^{*}} \\
\text { Arg }_{138} \\
\text { His }_{168} \\
\text { Asp }_{206} \\
\text { Tyr }_{214}\end{array}$ & $\begin{array}{l}\text { Phe } \\
\text { Asp } \\
\text { Pro } \\
\text { His } \\
\text { Leu } \\
\text { Arg } \\
\text { His } \\
\text { Glu } \\
\text { Tyr }\end{array}$ & $\begin{array}{l}\text { Thr }_{112} \\
\text { Asp }_{114} \\
\text { Gln }_{119} \\
\text { Tyr }_{198} \\
\text { Thr }_{245}\end{array}$ & $\begin{array}{l}\text { Leu } \\
\text { Asp } \\
\text { Gln } \\
\text { Tyr } \\
\text { Thr }\end{array}$ & $\begin{array}{l}\text { Phe }_{123} \\
\text { Asn }_{134} \\
\text { Phe }_{155} \\
\text { Asn }_{167} \\
\text { Asp }_{178} \\
\text { Gln }_{153} \\
\text { Tyr }_{175} \\
\text { Asp }_{177} \\
\text { Trp }_{179} \\
\text { Tyr }_{198} \\
\text { Tyr }_{214} \\
\text { His }_{121} \\
\text { Ile }_{135}{ }^{*}\end{array}$ & $\begin{array}{l}\text { Phe } \\
\text { Lys } \\
\text { Phe } \\
\text { Asn } \\
\text { Asp } \\
\text { GIn } \\
\text { Tyr } \\
\text { Asp } \\
\text { Trp } \\
\text { Tyr } \\
\text { Tyr } \\
\text { His } \\
\text { Leu }\end{array}$ \\
\hline
\end{tabular}

Asp-117, Asp-206 and His-168, are different in PADE (Table 1). The fourth alteration does not seem to be important, because Ile-135 in AAVDE is commonly replaced by its isomer, Leu, not only in PADE but also in other VDEs working in the Vx cycle. In turn, three remaining alterations may explain different range in $\mathrm{pH}$ values required by all known VDE working in the $\mathrm{Vx}$ cycle in comparison to that observed for DDE when extracts of diatom cells were used (Jakob et al., 2001). The His-168 protonation in DDEs probably carries out activation of the enzyme already at higher $\mathrm{pHs}$, while activation of typical VDEs, i.e. engaged in the Vx cycle, is shifted towards more acidic $\mathrm{pHs}$ due to the presence of the identified aspartates.

Recombinant PAVDE, which is described in this paper, may be consider as a good model to test this suggestion, as well as to verify the proposed molecular mechanism of de-epoxidases' activation caused by a decrease in $\mathrm{pH}$. Now, it is postulated that protonation of the four mentioned amino acid residues induced some loosening of the barrel and an increased water penetration. These water molecules compete with the Tyr hydroxyl group, thus reducing the strength of the hydrogen bond between His-121 and Tyr-214. The barrel is thought to be opened. In silico studies have also shown that disruption of hydrogen bond between His-121and Tyr-214 is reversible when the $\mathrm{pH}$ increases (Fufezan et al., 2012).

Among two remaining groups of amino acid of de-epoxidases, i.e. a putative Asc binding group, as well as amino acids postulated to be located closely of $\mathrm{Vx}$, all known $\mathrm{Vx}$ cycle VDEs and PADE differ only in one position (Table 1). In silico docking studies resulted in two possible models obtained from Asc docking in the VDE structure at $\mathrm{pH} 5$. In both cases, binding occurred at the same part of the protein, but Asc orientation and interactions with polypeptide chain were different. In these two models Thr-112, Asp-114, Gln-119, Tyr198 were postulated to interact with Asc (Fufezan et al., 2012). The four amino acid residues mentioned above are conserved for all known VDEs of the Vx cycle, but not for any diatom VDEs (Table 1). Among amino acid residues, considered to be located closely to Vx, Asn-134 of VDEs involved in the Vx cycle is replaced by Lys in PAVDE.

These single alterations, in light of the presented results, seem not to affect the kinetic properties of the tested enzymes under conditions which were applied in our experiments. On the other hand, active recombinant PAVDE gives a whole range of possibilities for detailed analysis of the individual amino acids' significance in various aspect of PADE activity, including structure, affinities to substrates and cofactors or kinetics of the catalyzed reaction. In our opinion, our data could be also treated as a helpful tool in understanding the role of diatom de-epoxidases in evolutionary success of diatoms in the earth ecosystems.

\section{Conflicts of Interest}

The authors declare no conflict of interest.

\section{REFERENCES}

Arnoux P, Morosinotto T, Saga G, Bassi R, Pignol D (2009) A structural basis for the $\mathrm{pH}$-dependent xanthophyll cycle in Arabidopsis thaliana. Plant Cell 21: 2036-2044

Bojko M, Brzostowska K, Kuczyńska P, Latowski D, Olchawa-Pajor M, Krzeszowiec W, Waloszek A, Strzałka K (2013a) Temperature effect on growth, and selected parameters of Phaeodactylum tricornutum in batch cultures. Acta Biochim Pol 60: 861-864

Bojko M, Olchawa-Pajor M, Tuleja U, Kuczyńska P, Strzałka W, Latowski D, Strzałka K (2013b) Expression of three diadinoxanthin de-epoxidase genes of Phaeodacylum tricornutum in Escherichia coli Origami b and BL21 strain. Acta Biochim Pol 60: 857-860

Bugos RC, Hieber AD, Yamamoto HY (1998) Xanthophyll cycle enzymes are members of the lipocalin family, the first identified from plants. J Biol Chem 273: 15321-15324

Hieber AD, Bugos RC, Yamamoto HY (2000) Plant lipocalins: violaxanthin de-epoxidase and zeaxanthin epoxidase. Biochim Biophys Acta 1482: 84-91.

Coesel S, Obornik M, Varela J (2008) Evolutionary origins and functions of the carotenoid biosynthetic pathway in marine diatoms. PLOS ONE 3: e2896 https://doi.org/10.1371/journal.pone.0002896

Charron JB, Ouellet F, Pelletier M, Danyluk J, Chauve C, Sarhan F (2005) Identification, expression, and evolutionary analyses of plant lipocalins. Plant Physiol 139: 2017-2028. https://doi.org/10.1104/ pp.105.070466.

Eskling M, Arvidsson PO, Akerlund H-E (1997) The xanthophyll cycle, its regulation and components. Physiol Plant 100: 806-816

Fufezan C, Simionato D, Morosinotto T (2012) Identification of key residues for $\mathrm{pH}$ dependent activation of violaxanthin de-epoxidase from Arabidopsis thaliana. PLOS ONE 7: e35669. https://doi. org/10.1371/journal.pone.0035669

Goss R, Jakob T (2010) Regulation and function of xantophyll cycle-dependent photoprotection in algae. Photosynth Res 106: 103-122. https://doi.org/10.1007/s11120-010-9536-x

Goss R, Lohr M, Latowski D, Grzyb J, Vieler A, Wilhelm C, Strzałka $\mathrm{K}$ (2005) Role of hexagonal structure-forming lipids in diadinoxanthin and violaxanthin solubilization and de-epoxidation. Biochemistry 44: 4028-4036

Grouneva I, Jakob T, Wilhelm C, Goss R (2006) Influence of ascorbate and $\mathrm{pH}$ on the activity of the diatom xanthophyll cycle-enzyme 
diadinoxanthin de-epoxidase. Physiol Plant 126: 205-211. https://doi. org/10.1111/j.1399-3054.2006.00613.x

Grzyb J, Latowski D, Strzałka K. (2006) Lipocalin - a family portrait. J Plant Physiol 163: 897-915

Guillard RRL, Ryther JH (1962) Studies of marine planktonic diatoms. I. Cyclotella nana Hustedt, and Detonula confervacea (cleve) Gran. Can J Microbiol 8: 229-239

Havir EA, Tausta LS, Peterson RB (1997) Purification and properties of violaxanthin de-epoxidase from spinach. Plant Sci 123: 57-66

Holden H, Rypniewski WR, Law J, Rayment I (1987) The molecular structure of insecticyanin from the tobacco hornworm Manduca sexta L. at 2.6 A resolution. EMBO J 6: 1565-1570

Jakob T, Goss R, Wilhelm CJ (2001) Unusual pH-dependence of diadinoxanthin de-epoxidase activation causes chlororespiratory induced accumulation of diatoxanthin in the diatom Phaeodactylum tricornutum. Plant Physiol 158: 383-390. https://doi.org/10.1078/0176-161700288

Laemmli UK (1970) Cleavage of structural proteins during assembly of head of bacteriophage-T4. Nature 227: 680-685. https://doi. org/10.1038/227680a0

Latowski D, Åkerlund H-E, Strzałka K (2004) Violaxanthin de-epoxidase, the xanthophyll cycle enzyme, requires lipid inverted hexagonal structures for its activity. Biochemistry 43: 4417-4420

Latowski D, Grzyb J, Goss R, Strzałka K (2007) Role of non-bilayer lipids in molecular mechanism of violaxanthin and diadinoxanthin de-epoxidation in the xanthophyll cycle. Curr Adv Biochem Cell Biol Plant Lipids, pp 169-172

Latowski D, Kuczyńska P, Strzałka K (2011) Xanthophyll cycle - a mechanism protecting plants against oxidative stress. Redox Rep 16: 78-90. https://doi.org/10.1179/174329211X13020951739938

Latowski D, Kruk J, Burda K, Skrzynecka-Jaskier M, Kostecka-Gugała A, Strzałka K (2002) Kinetics of violaxanthin de-epoxydase by violaxanthin de-epoxydase, a xantophyll cycle enzyme, is regulated by membrane fluidity in model lipid bilayers. Eur J Biochem 269: 46564665. https://doi.org/10.1046/j.1432-1033.2002.03166.x

Lohr M, Wilhelm C (1999) Algae displaying the diadinoxanthin cycle also possess the violaxanthin cycle. Proc Nat Acad Sci USA 96: 8784-8789. https://doi.org/10.1073/pnas.96.15.8784
Lohr M, Wilhelm C (2001) Xanthophyll synthesis in diatoms: quantification of putative intermediates and comparison of pigment conversion kinetics with rate constants derived from a model. Planta 212: $382-391$

Lowry OH, Rosebrough NJ, Farr AL, Randall RJ (1951) Protein measurement with the Folin phenol reagent. J Biol Chem 193: 265-275

Montsant A, Allen AE, Coesel S De Martino A, Falciatore A, Mangogna M, Siaut M Marc Heijde M, Jabbari K, Maheswari U, Rayko E, Vardi A, Apt KE, Berges JA, Chiovitti A, Davis AK, Thamatrakoln K, Hadi MZ, Lane TW, Lippmeier JC, Martinez D, Parker MS, Pazour GJ, Saito MA, Rokhsar DS, Armbrust EV, Bowler C (2007) Identification and comparative genomic analysis of signalic and regulatory components in the diatom Thalassiosira pseudonana. J Phycol 43: 585-604

Rockholm DC, Yamamoto HY (1996) Violaxanthin de-epoxidase. Plant Physiol 110: 697-703

Siaut M, Heijde M, Mangogna M, Montsant A, Coesel S, Allen A, Monfredonia A, Falciatore A, Bowler C (2007) Molecular toolbox for studying diatom biology in Phaeodactylum tricornutum. Gene 406: 23-35. https://doi.org/10.1016/j.gene.2007.05.022

Simionato D, Basso S, Zaffagnini M, Lana T, Marzotto F, Trost P, Morosinotto $T$ (2015) Protein redox regulation in the thylakoid lumen: The importance of disulfide bonds for violaxanthin de-epoxidase. FEBS Lett 589: 919-923. https://doi.org/10.1016/j.febslet.2015.02.033

Stransky H, Hager A (1970) The carotenoid pattern and occurrence of the light - induced xanthophyll cycle in various classes of algae. VI. Chemosystematic study. Arch Microbiol 73: 315-323. https://doi. org/10.1007/BF00412298

Yamamoto HY (1979) Biochemistry of the violaxanthin cycle in higher plants. Pure Appl Chem 51: 639-648. https://doi.org/10.1351/ pac197951030639

Yamamoto HY (1985) Xanthophyll cycles. Methods Ensymol 110: 303312. 